\title{
A busca pela efetividade do direito à educação: análise da atuação de uma Promotoria de Justiça da Infância e Juventude do interior paulista
}

\section{The search for effectiveness of the right to education: analysis of the Infancy and Youth Public Prosecutor's office of Justice role from a municipality of São Paulo State}

\author{
Adriana A. Dragone Silveira ${ }^{1}$
}

\begin{abstract}
RESUMO
O presente artigo analisa como o Ministério Público, instituição concebida na Constituição Federal de 1988, para defender o regime democrático e os interesses sociais e individuais indisponíveis, atuou para efetivar o direito à educação, ou seja, a garantia de um direito social positivado na legislação como direito de todos e dever do Estado. Para tanto, analisou-se a atuação da Promotoria da Justiça da Infância e Juventude do município de Ribeirão Preto. Da Promotoria estudada destaca-se a atuação crescente nos últimos anos, envolvendo diferentes solicitações, desde a requisição do acesso e permanência à educação infantil, ao ensino fundamental, ao ensino médio, às escolas próximas da residência, questionamentos sobre a qualidade de ensino, incentivos à gestão democrática do ensino público, entre outros assuntos. Outro importante aspecto do trabalho nessa Promotoria é o envolvimento da sociedade civil na discussão das prioridades por meio da realização de audiências públicas.

Palavras-chave: Direito à educação básica; Ministério Público; Infância e Juventude; Controle social.
\end{abstract}

\begin{abstract}
The present article analyzes how the Public Prosecution Service, institution conceived on the Brazilian Federal Constitution of 1988 to plead the democratic regime and the indispensable social and individual interests, acted to
\end{abstract}

1 Doutora em educação pela Faculdade de Educação da Universidade de São Paulo (FEUSP), Brasil. E-mail: adragone@usp.br. 
accomplish the right to education, in other words, the warranty of a social right formulated on law as a right of all and duty of the State. Therefore, Infancy and Youth Public Prosecutor's office of Justice from the municipality of Ribeirão Preto was selected to this research. It shows crescent actions from that office on the last years, involving different requests concerning: access and remaining in Early Childhood education, elementary education, high school education, schools that are near to students' homes, doubts about the quality of education, incentives on the democratic administration of public education, among other affairs. Another important aspect of the study is the civil society involvement in priorities discussions through the realization of public audiences.

Keywords: Right to elementary education; Public Prosecution Service; Infancy and Youth; Social control.

\section{Introdução}

A legislação brasileira, principalmente a partir de 1988, com a Constituição Federal, contempla com muito detalhamento o direito à educação, além de prever mecanismos jurídicos que podem ser utilizados para a sua proteção e instituições para a sua defesa, como o Ministério Público (MP).

Os estudos e pesquisas sobre a atuação do MP na garantia do direito à educação ainda são escassos, tanto na área do Direito como da Educação, evidenciando-se os trabalhos de Castilho (2006), Martines Júnior (2006), Silveira (2006) e Souza Júnior (2006). Os dois últimos apresentam análises de experiências realizadas, respectivamente, pelo MP de São Paulo e de Goiás.

Este artigo tem como objetivo analisar a atuação do MP para a efetivação do direito à educação ${ }^{2}$, por meio da experiência da atuação da Promotoria de Infância e Juventude do município de Ribeirão Preto, buscando verificar a frequência, a origem, a natureza das solicitações feitas ao MP e/ou por ele demandadas ao poder público, além de procurar caracterizar as decorrências de suas ações.

Para empreender este objetivo julga-se pertinente apresentar inicialmente uma discussão do direito à educação, ainda que sucinta, relacionando-o com os direitos de cidadania e como direitos humanos, além de analisar a sua declaração na legislação brasileira.

2 Este artigo é resultado de parte da dissertação de mestrado da autora, financiada pelo Conselho Nacional de Desenvolvimento Científico e Tecnológico (CNPq), discutindo um dos casos estudados na pesquisa. 


\section{$O$ direito à educação: um direito social de todos e um dever do Estado}

A educação escolar ou formal, segundo Teixeira (1996), caracterizada como um direito individual a ser assegurado pelo Estado por ser considerada de interesse público, é recente em nossa história. De acordo com o educador, essa educação não deve ser vista como uma vantagem, mas como direito de cada um e dever público para a construção de uma sociedade democrática:

O direito à educação faz-se um direito de todos, porque a educação já não é um processo de especialização de alguns para certas funções na sociedade, mas a formação de cada um e de todos para a sua contribuição à sociedade integrada e nacional, que se está constituindo com a modificação do trabalho e do tipo de relações humanas. (TEIXEIRA, 1996, p. 60).

O direito à educação não compreende somente a dimensão individual, mas a social também, pois a formação de cada cidadão contribui para o desenvolvimento econômico, político e social de toda a sociedade. Acredita-se que a educação é um dos requisitos imprescindíveis para o acesso ao conjunto de bens e serviços disponíveis na sociedade. Dessa forma, nossa Constituição Federal de 1988 $(\mathrm{CF} / 88)$ declarou o direito à educação no conjunto dos direitos sociais, e definiu que este visa ao "pleno desenvolvimento da pessoa, seu preparo para o exercício da cidadania e sua qualificação para o trabalho" (BRASIL, 1988, art. 205).

A educação como direito inalienável do cidadão, segundo Cury (2002), impõe ao Estado o dever de oferecê-la gratuitamente, para que seja acessível a todos os cidadãos. Portanto, o direito à educação está inserido em uma perspectiva mais ampla dos direitos civis. Para o autor, o histórico da garantia de direitos não é uniforme em todos os países, sendo importante apreciar os determinantes socioculturais de cada um.

Para Marshall (1967), em seu clássico "Cidadania, Classe Social e Status", a educação estaria vinculada ao elemento social da cidadania ${ }^{3}$, sendo o sistema

3 O autor analisa o conceito de cidadania fazendo sua divisão em três "partes ou elementos": civil, política e social, divisão esta que tem como referência o desenvolvimento histórico da cidadania na Inglaterra. 
educacional uma das instituições responsáveis por fazer exercer esse direito. Para o autor:

O direito à educação é um direito social de cidadania genuíno porque o objetivo da educação durante a infância é moldar o adulto em perspectiva. Basicamente, deveria ser considerado não como um direito da criança freqüentar a escola, mas como o direito do cidadão adulto ter sido educado. (MARSHALL, 1967, p. 73).

Nesse sentido, para Marshall (1967), a educação envolve um direito individual e um dever público, pois o desenvolvimento da sociedade depende da educação de seus membros. Sendo assim, a educação primária na Inglaterra, no final do século XIX, era obrigatória e gratuita. A obrigatoriedade da educação primária, ainda segundo Marshall, fazia-se necessária, pois, além de estar relacionada ao direito intrínseco do cidadão para se desenvolver, está vinculada a um dever, do qual "nem a criança nem o pai pode[m] apreciar toda a sua extensão" para com a sociedade porque esta reconheceu que precisava de uma população educada (1967, p. 99).

Nesta breve descrição histórica do conceito de cidadania, Marshall (1967) destaca que o direito à educação está contemplado nos direitos de cidadania, mas cabe ressaltar ser ele também um direito humano, consagrado na Declaração Universal dos Direitos Humanos, proclamada pela Assembléia Geral da Organização das Nações Unidas (ONU), em 1948: "Todo homem tem o direito à instrução. A instrução será garantida, pelo menos nos graus elementares e fundamentais. A instrução elementar será obrigatória" (art. XXVI).

De acordo com Benevides Soares (1998), os direitos do cidadão podem coincidir com os direitos humanos, que são mais amplos e abrangentes, sendo então "universais, naturais e ao mesmo tempo históricos". São "naturais e universais porque vinculados à natureza humana, mas são históricos no sentido de que mudaram ao longo do tempo, num mesmo país, e o seu reconhecimento é diferente em países distintos, num mesmo tempo" (p. 43). Dessa forma, a educação, como direito humano, deve ser exigida, mesmo sem estar especificada na legislação de um país. 
Segundo Benevides Soares, do ponto de vista histórico, os direitos humanos estão classificados em três dimensões ou gerações ${ }^{4}$. O direito à educação surge no contexto de afirmação da segunda geração dos direitos, a dos direitos sociais.

As três dimensões históricas dos direitos humanos, apresentadas aqui por Benevides (1998), misturam-se com a evolução dos direitos de cidadania discutidos por Marshall (1967)5. Entretanto, o reconhecimento e a institucionalização de tais direitos se realizam de acordo com as realidades históricas e sociais de cada país. No Brasil, a evolução dos direitos de cidadania, considerando os elementos propostos por Marshall (1967), do processo dos direitos civis aos políticos e destes aos direitos sociais, não foi linear e nem cumulativa, como defende Campilongo, "ao contrário, de modo imperfeito, truncado e simultâneo, a luta pela cidadania desenvolveu-se e desenvolve-se em todas essas frentes" (1994, p. 31).

Cury (2002), ao fazer uma análise da importância do direito à educação, destaca que o caminho percorrido pelos países europeus, na consagração dos direitos na legislação, nem sempre foi o mesmo trilhado pelos países que vivenciaram a realidade de colonização, e principalmente naqueles que tiveram período de escravatura. Segundo o autor,

A conquista do direito à educação, nestes países, além de mais lenta, conviveu e convive ainda com imensas desigualdades sociais. Neles, à desigualdade se soma a herança de precon-

4 Para a autora, a primeira geração dos direitos humanos é a das liberdades individuais ou os chamados direitos civis - as liberdades consagradas no século XVIII com o liberalismo. A segunda dimensão, chamada de direitos sociais, surgida no século XIX e prosseguindo nos meados do século $\mathrm{XX}$, abrange todos aqueles direitos marcados pela luta dos trabalhadores, "são de caráter social mais geral, como o direito à educação, saúde, habitação, lazer e, novamente, segurança". No Brasil, são reconhecidos como "direitos do cidadão". Na terceira geração estão os direitos coletivos da humanidade relacionados "à defesa ecológica, à paz, ao desenvolvimento, à autodeterminação dos povos, à partilha do patrimônio científico, cultural e tecnológico" (1998, p. 45). O termo gerações é utilizado no sentido da evolução histórica e não no sentido biológico.

5 Turner (2001), ao discutir os elementos de cidadania propostos por Marshall, argumenta que esses foram corroídos porque as mudanças econômicas, a inovação tecnológica e a globalização transformaram a natureza do trabalho, da guerra e das relações sociais. Dessa forma deveriam ser acrescidos novos direitos globais às três formas de direitos identificados por Marshall, como: a um ambiente sem danos, à cultura e à terra aboriginal, e à identidade étnica. Enquanto os direitos de cidadania, discutidos por Marshall, tentaram proteger os indivíduos das mudanças do mercado, o novo regime de direitos globais tentou resguardar os seres humanos das consequências negativas do crescimento econômico, da tecnologia e, principalmente, as gerações futuras dos efeitos da degradação ambiental. Esses novos direitos globais, defendidos por Turner, assemelham-se aos direitos humanos de terceira geração discutidos por Benevides Soares (1998). 
ceitos e de discriminações étnicas e de gênero incompatíveis com os direitos civis. Em muitos destes países, a formalização de conquistas sociais em lei e em direito não chega a se efetivar por causa desses constrangimentos herdados do passado e ainda presentes nas sociedades. (CURY, 2002, p. 256-257).

A declaração do direito à educação como direito de todos, em nível constitucional no Brasil, já havia ocorrido a partir de 1934, sendo, no entanto, mais detalhada com a CF/88.

A atual Constituição Federal foi a primeira a declarar o direito à educação no conjunto dos direitos sociais, além de reafirmar que se constitui como direito de todos e dever do Estado e da família. Os deveres do Estado para com a educação estão definidos no artigo 208 da $\mathrm{CF} / 88^{6}$ :

I- ensino fundamental obrigatório e gratuito, assegurada, inclusive, sua oferta gratuita para todos os que a ele não tiveram acesso na idade própria;

II- progressiva universalização do ensino médio gratuito;

III- atendimento educacional especializado aos portadores de deficiência, preferencialmente na rede regular de ensino; IV- educação infantil, em creche e pré-escola, às crianças até 5 anos de idade;

V-acesso aos níveis elevados do ensino, da pesquisa e da criação artística, segundo a capacidade de cada um;

VI- oferta de ensino noturno regular, adequando às condições do educando;

VII- atendimento ao educando, no ensino fundamental, através de programas suplementares de material didático escolar, transporte, alimentação e assistência à saúde. (BRASIL, 1988, art. 208).

No conjunto dos deveres do Estado para com a educação básica, além do ensino fundamental e do ensino médio, é importante destacar que a $\mathrm{CF} / 88$ é a primeira a declarar o dever do Estado para garantir atendimento em creche e préescola às crianças pequenas, e como direito dos trabalhadores urbanos e rurais.

6 Cabe destacar que os incisos I e II foram alterados pela Emenda Constitucional (EC) $\mathrm{n}^{\circ}$ 14/96 e o inciso IV pela EC-53/2006. 
Na Lei de Diretrizes e Bases da Educação Nacional, de 1996 (LDB/96), as obrigações do Estado no dever de educar estão declaradas no artigo $4^{\circ}$, detalhando e ampliando os direitos elencados no artigo 208 da CF/88. Na LDB/96 a expressão "portadores de deficiências" é substituída por "educandos com necessidades educacionais especiais" e acrescida da gratuidade do atendimento educacional especializado, preferencialmente na rede regular de ensino.

Outra declaração quanto à oferta obrigatória pelo Estado foi a introdução do atendimento gratuito em creches e pré-escolas. Essa mesma LDB/96 trouxe outras importantes inovações para o direito à educação infantil, como o seu reconhecimento como primeira etapa da educação básica.

Um outro importante documento legal para a declaração do direito à educação é o Estatuto da Criança e do Adolescente de 1990 (ECA). Este Estatuto, no artigo 53, amplia as condições para a efetivação desse direito. O primeiro inciso desse artigo está presente na $\mathrm{CF} / 88$, mas há outros aspectos complementares do direito à educação, como o inciso II que garante às crianças e aos adolescentes o direito de serem respeitados por seus educadores, o inciso III, que possibilita a discussão pelas famílias dos critérios de avaliação do rendimento escolar adotados pela escola; e o inciso V, que favorece, segundo Oliveira (1995), a possibilidade de exigência do transporte escolar gratuito, na impossibilidade de atendimento do educando na escola próxima de sua residência.

Outro destaque importante para a compreensão do direito à educação é sua previsão como direito público subjetivo. Assim, a CF/88, ao estabelecer os deveres do Estado com a educação, declarou expressamente que "o acesso ao ensino fundamental obrigatório e gratuito é direito público subjetivo", e que o "não-oferecimento do ensino obrigatório pelo Poder Público, ou sua oferta irregular, importa responsabilidade da autoridade competente" (Art. $208, \S 1^{\circ}$ e $2^{\circ}$ ).

Segundo Duarte (2004), o direito público subjetivo:

[...] confere ao indivíduo a possibilidade de transformar a norma geral e abstrata contida num determinado ordenamento jurídico em algo que possua como próprio. A maneira de fazê-lo é acionando as normas jurídicas (direito objetivo) e transformando-as em seu direito (direito subjetivo). (DUARTE, 2004, p. 113).

Anos mais tarde, a LDB/96 acrescenta as partes que poderão acionar o Poder Público para exigir o acesso ao ensino fundamental como direito público subjetivo, incluindo nesse conjunto o MP. A mesma LDB/96 ainda determina 
que a negligência da autoridade competente não oferecendo o ensino obrigatório implica crime de responsabilidade.

A análise dos dados educacionais evidencia que muito ainda se deve fazer para que a legislação seja cumprida no Brasil. Apesar da expansão inegável do atendimento no ensino fundamental, principalmente após os meados da década de 1990, chegando aproximadamente a 97\% na taxa de escolarização líquida, não conseguimos universalizá-lo por completo. Além disso, segundo os resultados do Sistema de Avaliação da Educação Básica (SAEB) do INEP/MEC, $59 \%$ dos alunos, em 2001, que concluem a $4^{a}$ série apresentam níveis de rendimento escolar considerado "crítico" ou "muito crítico"; na educação infantil os dados do Censo de 2000 revelam que apenas 9,4\% das crianças de 0 a 3 anos têm acesso à creche, e a pré-escola é frequentada por $61,4 \%$ das crianças de 4 a 6 anos; no ensino médio, a taxa de escolarização líquida, em 2000, era de $33,3 \%$ (INEP/MEC, 2004).

Assegurar o direito à educação não é apenas oferecer vagas nas escolas, é necessário garantir a permanência dos alunos e é preciso haver uma escola de qualidade para todos.

A CF/88, dentre os princípios definidos para o ensino, afirma que se deve garantir "padrão de qualidade". A LDB/96 define como padrões mínimos de qualidade de ensino: "[...] a variedade e quantidade mínimas, por aluno, de insumos indispensáveis ao desenvolvimento do processo ensino-aprendizagem" (art. $4^{\circ}$, inciso IX). Como se pode observar, a linguagem é bastante simplista e abrangente o que, sem dúvida, dificulta a objetividade da cobrança. Segundo Oliveira e Araújo (2005), faz-se necessária a construção de indicadores de qualidade, possíveis de serem exigidos judicialmente.

A busca de todos os cidadãos brasileiros pela efetivação do acesso, da permanência e de um ensino de qualidade pode ser favorecida pela atuação do MP, no caso do estado de São Paulo, por meio da Promotoria de Justiça especializada na proteção dos direitos da infância e juventude.

\section{Funções institucionais do Ministério Público para a efetividade do direito à educação}

O trabalho do MP vai além das tradicionais funções criminais, assumindo uma função de zelar pelos direitos e garantias legais, atuando administrativa e/ou judicialmente. A CF/88 consolidou o MP como instituição responsável pela preservação do regime democrático, aplicando a legislação, defendendo 
a ordem jurídica e os interesses sociais e individuais indisponíveis. Da mesma forma, o ECA estabelece sua atuação para a garantia dos direitos relativos à infância e à adolescência.

$\mathrm{Na} \mathrm{CF} / 88$, o MP foi inserido em capítulo distinto daqueles destinados aos poderes do Estado, indicando a disposição de promovê-lo como instituição autônoma e independente.

Compete ao MP, segundo a $\mathrm{CF} / 88$, entre outras funções:

II- zelar pelo efetivo respeito dos Poderes Públicos e dos serviços de relevância pública aos direitos assegurados nesta Constituição, promovendo as medidas necessárias a sua garantia;

III- promover o inquérito civil e a ação civil pública, para a proteção do patrimônio público e social, do meio ambiente e de outros interesses difusos e coletivos;

IV- promover a ação de inconstitucionalidade ou representação para fins de intervenção da União e dos Estados, nos casos previstos nesta Constituição; (BRASIL, 1988, art. 129).

Após a promulgação da $\mathrm{CF} / 88$, várias leis infraconstitucionais instituíram direitos difusos e coletivos ${ }^{7}$ e ampliaram o campo de atribuições do MP, principalmente advindas do ECA.

No caso da educação, a sociedade pode fazer valer os seus direitos contra os abusos ou omissões do Estado por meio de instrumentos processuais como: o Mandado de Segurança, o Mandado de Injunção e a Ação Civil Pública. Assim também o MP pode fazê-lo pela via extrajudicial, utilizando-se de Inquérito Civil, Procedimento Administrativo e Sindicância.

$\mathrm{O}$ MP está autorizado a instalar o Inquérito Civil para investigar danos às crianças e aos adolescentes, garantir direitos fundamentais e verificar falhas da Administração na prestação de seus serviços básicos. Depois de esgotadas as investigações pelo Inquérito Civil, se o MP verificar a inexistência de fundamento para a propositura da Ação Civil Pública, promoverá o arquivamento com as devidas justificativas fundamentadas.

No processo de investigação do descumprimento dos direitos e garantias legais o MP pode requisitar informações por meio de notificações, bem como

7 Interesses difusos são aqueles compartilhados por um grupo indeterminável de lesados, sendo o objeto desses interesses indivisível. Já os interesses coletivos são compartilhados por um grupo determinável de lesados e o objeto desses interesses é indivisível (MAZZILLI, 2004). 
exigir exames, perícias e documentos, além de promover inspeções às instituições públicas e privadas.

Esses poderes requisitórios e investigatórios concedidos ao membro do MP pelo ECA, de acordo com Digiácomo, servirão "não apenas para permitir a coleta de elementos de convicção indispensáveis à propositura da demanda judicial, mas também para tentativa da solução do problema pela via administrativa" (2004, p. 334).

A instituição MP é composta pelo MP da União, que compreende o MP Federal, MP do Trabalho, MP Militar, MP do Distrito Federal e dos Territórios; e o MP dos $\operatorname{Estados}^{8}(\mathrm{CF} / 88$, art. 128).

Os membros do MP - Promotores e Procuradores de Justiça ${ }^{9}$ - no exercício de suas funções têm independência funcional para exercer suas funções para com outros membros ou órgãos da instituição, respeitando suas funções delimitadas pela legislação. Além da independência funcional o MP possui autonomia funcional, que "é a liberdade que o Ministério Público tem, como instituição, para, em face de outros órgãos ou instituições do Estado, tomar suas decisões sem ater-se a instruções ou decisões de outros órgãos ou Poderes do Estado" (MAZZILLI, 2004, p. 34).

A independência funcional é vista com limites por alguns autores como Silva (2001), Kerche (2002) e Martines Júnior (2006), pois pode constituir-se na imparcialidade na defesa dos interesses coletivos e difusos, mas também pode dificultar a criação e o cumprimento de políticas institucionais.

As Promotorias de Justiça, de acordo com a Lei Orgânica do MP de São Paulo, poderão ser desdobradas em: Especializadas, Criminais, Cíveis e Cumulativas ou Gerais. As Promotorias Especializadas atuam nas seguintes áreas: Acidentes de Trabalho, Família, Infância e Juventude, Registros Públicos, Meio Ambiente, Consumidor, Mandados de Segurança, Cidadania, Habitação e Urbanismo, Execuções Criminais, Tribunais do Júri e Militar. As Promotorias Criminais atuam na esfera penal e as Cíveis são responsáveis pela esfera civil. Já as Promotorias Cumulativas ou Gerais, mantêm funções simultâneas da Promotoria Civil e Criminal.

A efetividade do direito à educação no estado de São Paulo pode ser objeto de aplicação por diferentes Promotorias do MP, valendo-se dos cargos especializados de Promotor de Justiça da Infância e da Juventude que, segundo a Lei

8 A organização do MP do estado de São Paulo é normatizada pela Lei Complementar Estadual no 734, de 26 de novembro de 1993, que instituiu a Lei Orgânica do MP de São Paulo.

9 O Promotor de Justiça é um membro do MP de primeira instância e o Procurador de Justiça membro de segunda instância, sendo a promoção realizada por merecimento e por antiguidade. A chefia da instituição denomina-se Procurador-Geral de Justiça. 
Orgânica do MP, deve atuar para a "proteção integral da criança e do adolescente, bem como as relações jurídicas decorrentes de seu regime jurídico especial, desde que de competência da Justiça da Infância e da Juventude". Pode valer-se, igualmente, do Promotor de Justiça da Cidadania, cujas funções são de "garantia de efetivo respeito dos Poderes Públicos e dos serviços de relevância pública aos direitos assegurados nas Constituições Federal e Estadual, da probidade e legalidade administrativas e da proteção do patrimônio público e social" (SÃO PAULO, 1993, art. 295, incisos IV e IX).

O MP, de acordo com a legislação, tem funções e instrumentos jurídicos para defender violações dos direitos consagrados, incluindo nesse conjunto o direito à educação. Entretanto, Martines Júnior (2006) destaca que a abrangência do papel do MP para a efetividade do direito à educação deve ir além da requisição de vagas:

A intervenção ministerial reclamada está longe de se limitar a uma ou outra ação específica, tais como atuar em relação a uma criança ou adolescente ausente da escola, ou a obrigar o Poder Público a arrumar uma vaga em creche ou escola do ensino básico. Não. O Ministério Público precisa cumprir o seu papel de forma muito mais abrangente, cobrando posturas do Poder Público, da família e da sociedade, auxiliando no desenvolvimento de políticas públicas educacionais e exigindo suas implementações, fiscalizando a qualidade do ensino oferecido e, de uma maneira geral, exigindo o cumprimento da norma que definiu a criança e o adolescente como prioridades, acima das demais. [...] (MARTINES JÚNIOR, 2006, p. 316-317).

Desta forma, destaca-se como relevante relatar como o MP, por meio de uma Promotoria da Infância e Juventude, desenvolveu sua atuação para a efetividade do direito à educação.

\section{A experiência da Promotoria da Infância e Juventude de Ribeirão Preto}

Como determinam o ECA e a Lei Orgânica do MP de São Paulo, os Promotores de Justiça da Infância e Juventude devem atuar na proteção integral 
da criança e do adolescente, ou seja, estudantes da faixa etária em que se enquadram os alunos da educação básica. Essa especialização de atuação do MP fundamentou a escolha por essa Promotoria para analisar as ações desempenhadas para a efetivação do direito à educação básica.

Para este estudo a abordagem metodológica utilizada foi a qualitativa, com enfoque de estudo de caso. Para a coleta de dados, recorreu-se a entrevistas e à análise documental das ações judiciais, dos procedimentos extrajudiciais e de demais documentos formulados pela Promotoria que evidenciassem ações do MP para o controle social do direito à educação, no período de 1997 a 2004.

Localizado no interior do estado de São Paulo, o município de Ribeirão Preto apresentava, em 2005, a população estimada de 543.885 habitantes. O MP, nessa localidade, funcionando em prédio próprio, estava organizado em duas Promotorias, uma de Justiça Criminal e uma de Justiça Civil.

A Promotoria da Infância e Juventude contava com a seguinte estrutura administrativa: dois oficiais de promotoria, um assistente técnico e vários estagiários. O Promotor da Justiça da Infância e Juventude atuava como responsável, além dessa área, pela Promotoria de Justiça do Meio Ambiente e de Conflitos Fundiários.

O Promotor da Justiça da Infância e Juventude ingressou no MP em 1984, e a sua primeira Comarca como titular foi na região de Ribeirão Preto. Trabalhava neste município desde 1994. Nas Comarcas em que trabalhou, sempre atuou na área da Infância e Juventude, entretanto, o fazia de maneira mais especializada nos últimos anos. O Promotor afirmou identificar-se muito com a área da infância e juventude, principalmente depois do ECA. Na Promotoria da Infância e Juventude, a sua atuação estava direcionada para a área de direitos difusos e coletivos, que seria o controle das políticas públicas e o cumprimento dos direitos fundamentais, fazendo, também, o acompanhamento de medidas socioeducativas de internação de uma das unidades da Fundação Estadual do Bem-Estar do Menor (Febem).

$\mathrm{Na}$ tentativa de buscar uma "legitimação real" para a atuação do MP, o Promotor de Justiça da Infância e Juventude de Ribeirão Preto consolidou a realização anual de audiências públicas, com a participação da sociedade civil, para definir as prioridades de atuação.

De acordo com o Promotor, nos primeiros anos das audiências públicas, as prioridades na área da infância e juventude eram o combate ao trabalho infantil, à venda e a entrega de bebidas alcoólicas às crianças e aos adolescentes. A educação aparecia com menos força, sendo abordados os problemas de vagas, sobretudo na pré-escola. Entretanto, nos últimos anos, a "educação apareceu como a grande prioridade, praticamente dominando o debate nas audiências públicas". 
O MP em Ribeirão Preto contava também, desde 2003, com a experiência da "Promotoria de Justiça da Comunidade". Esse trabalho era realizado pelo Promotor de Justiça da Infância e Juventude e pelo Promotor de Justiça da Habitação e Urbanismo. Nesta atividade, o MP se desloca até uma região carente da cidade. Acompanham os Promotores de Justiça os oficiais de promotoria e um Procurador do Estado, que faz a assistência judiciária nos casos dos interesses individuais, junto com os seus estagiários. $\mathrm{O}$ atendimento é feito semanalmente em uma escola, com o apoio das Associações de Bairro.

No período analisado foram instaurados 48 procedimentos extrajudiciais e 5 processos judiciais. A Promotoria de Justiça da Infância e Juventude teve como maior demanda as solicitações para o acesso à educação e à permanência do aluno ( 32 documentos). Outros procedimentos e processos judiciais (16 no total) discutiram temas que estão mais associados à qualidade da educação, o que revela uma preocupação de que garantir o direito à educação não é apenas efetuar a matrícula da criança e do adolescente. É preciso que a escola tenha estrutura física apropriada e equipe completa de funcionários para o atendimento com qualidade dos alunos. A Promotoria de Justiça da Infância e Juventude, quando demandada, exigiu também explicações dos órgãos competentes com relação às questões mais ligadas ao currículo e ao atendimento pedagógico.

Das demandas por vagas destaca-se a expressiva atuação do MP em Ribeirão Preto para assegurar o direito à educação infantil. $\mathrm{O}$ atendimento em pré-escola pública em 2000 , no município, estava abaixo de $50 \%$ do total da população na faixa etária de 4 a 6 anos e a creche tinha um percentual ainda muito mais baixo, apenas $11 \%$ da população de 0 a 3 era atendida, incluindo a rede privada, o que demonstra a necessidade de medidas por parte do MP para fazer cumprir um direito assegurado constitucionalmente. Além de requisição de vagas, a Promotoria instaurou procedimentos administrativos e judiciais para exigir a regularização de escolas particulares de educação infantil.

Verificando o período em que foram instaurados os procedimentos extrajudiciais e ingressadas as ações judiciais, pode-se notar que a atuação tem expressivo aumento a partir de 2002. Sobre esse aspecto, atenta-se para o fato de que a educação obteve prioridade no Plano Geral de Atuação do MP para o Estado de São Paulo, na área da Infância e Juventude, nos anos de 2003 e 2004, assim como nos Programas de Atuação da Promotoria.

O Promotor de Justiça, na busca de solucionar as demandas administrativamente, ingressou, no período analisado, com cinco processos judiciais, com o objetivo de, segundo ele mesmo, "esgotar", no âmbito administrativo, as possibilidades de atuação do MP, fazendo uso do Inquérito Civil e da possibilidade do ajustamento de conduta. 
Analisando a origem da atuação da Promotoria da Infância e Juventude, pode-se notar que mais de $50 \%$ das demandas são originadas de representações ou solicitações por escrito. Cabe destacar, também, a existência da atuação do MP movida por notícias de jornais e de telejornais, noticiando a violação do direito à educação e a própria iniciativa da Promotoria desencadeada em reuniões com entidades e/ou membros da sociedade civil.

A atuação do MP em Ribeirão Preto foi solicitada por diferentes autores, assim como por meio da sociedade civil organizada em Associações de Bairros e ONGs, pelos Conselhos Tutelares, Conselho Municipal de Educação e individualmente, ou seja, por cidadãos sem vínculos com entidades. As demandas mais frequentes tiveram como autores das representações os Conselhos Tutelares e os pais de alunos.

Outro trabalho em destaque da Promotoria da Infância e Juventude diz respeito à gestão democrática, incentivando a formação dos Grêmios Estudantis e a criação de Conselhos Regionais de Conselhos de Escolas que têm buscado discutir os problemas das escolas, com representantes de diferentes segmentos. Segundo o Promotor de Justiça, a melhoria da qualidade da escola pública, com o atendimento dos interesses da população, seria possível com a efetivação da gestão democrática.

Segundo o Assistente Técnico, o Conselho Regional de Conselhos de Escola tem abordado e resolvido questões, que não são exclusivas da região a que pertencem as escolas, pois as discussões dos problemas e as soluções propostas afetam toda a rede pública. As discussões, no âmbito do Conselho, são fortalecidas com a possibilidade de notificação pelo MP de Secretários Municipais, da Dirigente Regional de Ensino e de outras autoridades para comparecerem às reuniões.

Em muitos dos procedimentos a solução para os casos investigados estava se viabilizando por meio do diálogo entre o poder público, Conselho Municipal de Educação, Conselhos Tutelares e representantes de Conselhos de Escolas. Para o Promotor de Justiça, o resultado das ações seria mais rápido se trabalhasse exclusivamente a partir das prioridades definidas com a sociedade civil.

A análise das consequências da atuação do MP neste município não se resume no apontamento numérico das matrículas efetuadas, das obras e mudanças realizadas, pois se acredita que a mobilização da sociedade ocorrida durante o processo também é um resultado muito positivo. Acerca dos efeitos "concretos" enumeram-se: reforma de escola para atendimento da demanda; regularização de vagas com a conclusão e/ou ampliação de escolas por meio de cobrança do MP ao poder público; regularização das matrículas quando as crianças e adolescentes que estavam sem vagas ou estudando em escolas distantes de suas residências eram nomeados; abertura de salas de aulas; cessão de salas de aulas em 
escolas municipais para abertura de classes de ensino médio pela rede estadual; disponibilização de área institucional pela Prefeitura com a previsão de construção da escola pelo governo estadual; projetos para a construção de escolas pelo governo estadual; readequação do prédio para atendimento dos alunos; aulas de reforço; tratamento psicológico; reposição de aulas; continuação dos estudos para os alunos expulsos das escolas; alteração em resolução sobre os critérios de matrículas na rede municipal; atendimento às irregularidades apontadas pela Equipe de Vigilância Sanitária por meio de pequenas reformas nas unidades escolares.

\section{Considerações finais}

Após a $\mathrm{CF} / 88$ o MP passou a ter mais funções e instrumentos jurídicos para atuar amplamente na área dos interesses sociais, sendo que o ECA ampliou as atribuições dos membros desta instituição para garantir os direitos e os interesses das crianças e dos adolescentes, incluindo nesse conjunto o direito à educação, o qual, relacionado ao desenvolvimento da cidadania, envolveria, segundo Marshall (1967), um direito individual do cidadão, mas também um dever para com a sociedade. Nesse aspecto, é formalizado em nossa Carta Constitucional como direito de todos, cabendo ao Estado e à família o dever de garanti-lo. As obrigações do Estado para com o direito educacional são elencadas no artigo 208 da CF/88, sendo essa definição importante para a requisição deste direito.

O MP em Ribeirão Preto, por meio da Promotoria de Justiça da Infância e Juventude, procurou, no período analisado, atuar ativamente na busca pela efetividade do direito à educação. Sua intervenção não se restringiu à concretização do direito à matrícula, mas atuando de maneira mais abrangente e, em conjunto com a sociedade, reclamou o cumprimento por parte do Poder Público, da família e da sociedade do que está estabelecido na legislação.

Da análise do trabalho daquela Promotoria de Justiça destacam-se algumas características que a diferenciam, possibilitando essa atuação mais abrangente no controle social do Estado, como: a realização de Audiências Públicas para o estabelecimento de prioridades de atuação do MP e para divulgação do trabalho como mecanismo de garantia de direitos; ampla abertura da instituição para o recebimento de representações da sociedade civil; desenvolvimento de trabalho "fora do gabinete" com a Promotoria da Comunidade; a criação de Conselhos Regionais Escolares. 
Do MP em Ribeirão Preto ainda destacam-se alguns diferenciais como: a existência de um Assistente Técnico, como um profissional especializado na área para auxiliar o Promotor de Justiça; estrutura física bem equipada; atuação do Promotor de Justiça em um número menor de áreas especializadas; o longo período de atuação do Promotor de Justiça nesta região e na área da Infância e Juventude.

Essas características não são comuns a todas as Promotorias de Justiça, mas estão mais dependentes do perfil do membro do MP, como foi verificado em Silveira (2006). Para fortalecer e tornar mais efetiva a atuação do MP se faz necessário estabelecer políticas institucionais e fortalecer o trabalho em conjunto com a sociedade, possibilitando à instituição o conhecimento das reais demandas e fortalecendo a cobrança, contribuindo, desta forma, como mecanismo de pressão junto aos poderes públicos.

A existência da garantia legal do direito à educação e da existência de mecanismos para a sua defesa não são suficientes para que ela se efetive com qualidade para todos, sendo necessário transformar/concretizar em políticas públicas os direitos já reconhecidos constitucionalmente, exigindo do poder público, seja por meio judicial ou pela cobrança da sociedade civil organizada a sua realização, tendo o MP um importante papel em seu sucesso.

\section{REFERÊNCIAS}

BENEVIDES SOARES, M. V. M. Cidadania e Direitos Humanos. Cadernos de Pesquisa, São Paulo, n. 104, p. 39-46, jul. 1998.

BRASIL. Constituição da República Federativa do Brasil de 1988. Diário Oficial da União Brasília, 05 out. 1988.

. Lei $n^{\circ} 8.069$, de 13 de julho de 1990. Dispõe sobre o Estatuto da Criança e do Adolescente e dá outras providências. Diário Oficial da União, República Federativa do Brasil, Brasília, DF, 16 jul. 1990. Disponível em: <http://www. planalto.gov.br>. Acesso em: 6/09/2007.

. Lei $n^{o}$. 9.394, de 20/12/1996. Estabelece as Diretrizes e Bases da Educação Nacional. Disponível em: <http://www.presidencia.gov.br/ccivil_03/ Leis/L9394.htm >. Acesso em: 20/01/2007. 
CAMPILONGO, C. F. Os desafios do judiciário: um enquadramento teórico. In: FARIA, J. E. Direitos Humanos, Direitos Sociais e Justiça. São Paulo: Malheiros, 1994.

CASTILHO, E. W. V. Direito à educação e Ministério Público. 2006. Disponível em: <http://www.acaoeducativa.org.br/downloads/EST1.pdf>. Acesso em: $5 / 01 / 2008$.

CURY, C. R. J. Direito à educação: direito à igualdade, direito à diferença. Cadernos de Pesquisa, São Paulo, n. 116, p. 245-262, 2002.

DIGIÁCOMO, M. J. Instrumentos Jurídicos para garantia do direito à educação. In: LIBERATI, W. D. Direito à educação: uma questão de justiça. São Paulo: Malheiros, 2004.

DUARTE, C. S. Direito público subjetivo e políticas educacionais. São Paulo em Perspectiva, São Paulo, n. 18 (2), p. 113-118. 2004.

INSTITUTO NACIONAL DE ESTUDOS E PESQUISAS EDUCACIONAIS ANÍSIO TEIXEIRA/ MINISTÉRIO DA EDUCAÇÃO (Inep/MEC). Os desafios do Plano Nacional de Educação. Brasília: Inep/MEC, 2004.

KERCHE, F. O Ministério Público no Brasil: autonomia, organização e atribuições. Tese (Doutorado) - Faculdade de Filosofia, Letras e Ciências Humanas, Universidade de São Paulo, São Paulo, 2002. p. 168.

MARSHALL, T. H. Cidadania, classe social e status. Rio de Janeiro: Zahar, 1967.

MARTINES JÚNIOR, E. Educação, Cidadania e Ministério Público: o artigo 205 da Constituição e sua abrangência. Tese (Doutorado em Direito) - Pontifícia Universidade Católica de São Paulo, São Paulo, 2006, 446f.

MAZZILLI. H. N. Ministério Público. São Paulo: Damásio de Jesus, 2004.

OLIVEIRA, R. P. Educação e cidadania: o Direito à educação na Constituição de 1998 da República Federativa do Brasil. Tese (Doutorado) - Faculdade de Educação, Universidade de São Paulo, São Paulo, 1995, 179p.

; ARAUJO, G. C. Qualidade do ensino: uma nova dimensão da luta pelo direito à educação. Revista Brasileira de Educação, n. 28, p. 5-23, jan./ fev./mar. 2005. 
SÃO PAULO. Lei Complementar Estadual nº 734, de 26 de novembro de 1993. Lei Orgânica do Ministério Público de São Paulo (LOEMP/SP). Disponível em: <http://www.mp.sp.gov.br/conselho/lei_organica_sp.htm >. Acesso em: 10/06/2006.

SILVA, C. A. Justiça em Jogo: Novas facetas da atuação dos promotores de justiça. São Paulo: Editora da Universidade de São Paulo, 2001.

SILVEIRA, A. A. D. Direito à educação e o Ministério Público: uma análise da atuação de duas Promotorias de Justiça da Infância e Juventude do interior paulista. Dissertação (Mestrado em Educação) - Faculdade de Educação, Universidade de São Paulo, São Paulo, 2006, 261f.

SOUZA JÚNIOR, Edson José de. Efetividade do direito à educação: o caso do Ministério Público em Goiânia (2001-2006). Dissertação (Mestrado em Educação) - Universidade Federal de Goiás, Goiânia, 2006, 190f.

TEIXEIRA, A. Educação é um direito. Rio de Janeiro: Editora UFRJ, 1996.

TURNER, B. S. The erosion of citizenship. British Journal of Sociology, n. 52, p. 189-209, 2001.

Texto recebido em 08 de janeiro de 2009.

Texto aprovado em 21 de março de 2009. 